\title{
Factors Associated with Recovery Rate Among Severely Malnourished Children Enrolled in Outpatient Therapeutic Program at Kitui County Hospital, Kenya
}

\author{
Dorothy Mbaya*, Lucy K. Gitonga \\ Department of Nursing, Chuka University, Chuka, Kenya \\ Email address: \\ dmicheni10@gmail.com (D. Mbaya) \\ *Corresponding author
}

To cite this article:

Dorothy Mbaya, Lucy K. Gitonga. Factors Associated with Recovery Rate Among Severely Malnourished Children Enrolled in Outpatient Therapeutic Program at Kitui County Hospital, Kenya. American Journal of Pediatrics. Vol. 3, No. 6, 2017, pp. 62-67. doi: 10.11648/j.ajp.20170306.11

Received: January 24, 2017; Accepted: February 17, 2017; Published: October 31, 2017

\begin{abstract}
Advent of ready to use therapeutic food made it possible to treat children with severe acute malnutritionas outpatients. Studies have reported that recovery rate among children enrolled in outpatient therapeutic program is below the acceptable standard $(<75 \%)$. The objective of the study was to determine the factors associated with recovery rate among children aged 6-59 months enrolled in outpatient therapeutic program at Kitui County Hospital. A cross sectionalstudy was carried out where we consecutively recruited104 children with severe acute malnutrition. Information was obtained from mothers/guardians regarding demographic, socio-economic, socio-cultural and medical related factors. Anthropometric measurements of the children were conducted at the fourth visit. Chi-square test and odds ratio were used to determine the association between recovery rate and independent variables. Binary logistic regression analysis was performed to determine predictors of recovery. The recovery rate was $73.3 \%$ [95\% CI 64.6\%-81.9\%]. Significant predictors of recovery were absence of co-morbidity in the previous month $[\mathrm{AOR}=5.23 ; 95 \% \mathrm{CI}=1.36-20.10 ; \mathrm{P}=0.016]$, receiving antibiotic $[\mathrm{AOR}=13.06$; $95 \% \mathrm{CI}=3.01-56.65 ; \mathrm{P}=0.001]$ and initiation ofcomplementary feeding at 6 months of age $[\mathrm{AOR}=8.86 ; 95 \% \mathrm{CI}=2.20-35.68$; $\mathrm{P}=0.002]$. Being a house wife was an independent predictor of recovery $[\mathrm{AOR}=5.26 ; 95 \% \mathrm{CI}=1.33-20.87 ; \mathrm{P}=0.018]$. The recovery rate was slightly below the acceptable standards. Special focus should be given on predictors of recovery rate like administration of antibiotics, prompt and appropriate management of co-morbidities with appropriate care during the illness and initiation of complementary feeding at the age of 6 months.
\end{abstract}

Keywords: Children, Recovery Rate, Severe Acute Malnutrition

\section{Introduction}

Severe acute malnutrition (SAM) is defined as a low weight for height (below - 3Z scores of the median World Health Organization (WHO) growth standards), visible wasting, nutritional oedema or middle upper arm circumference (MUAC) of less than 115 millimetres in children 6-59 months [1]. It is an unstable condition or form of malnutrition resulting from a relatively short period of sustained nutritional deficit. It is estimated that nearly 20 million children worldwide are severely malnourished, most of them live in South Asia and Sub-Saharan Africa [2]. WHO estimates indicate that mortality among children with SAM is
5 to 20 times higher compared to well-nourished children [2]. About 1 million children die every year from severe acute malnutrition [3].

Malnutrition in all its forms remains a major public health problem in the developing world. It is an underlying factor in over $50 \%$ of the deaths and increased morbidity among children less than 5 years annually. Up to $41 \%$ of these preventable deaths occur in sub-Saharan Africa [4]. Malnutrition rates among children aged below five years in Kenya has not changed much over the past decade. The Kenya Demographic and Health Survey 2008 reported that 
$35 \%$ of children under five were stunted while the proportion of severely stunted was $14 \%$. In Kitui County (within Kenya) the prevalence of stunting with below -2 WHZ score was $37.9 \%$ in children less than five years old [5].

Over the past decade there has been a global initiative to shift from facility-based treatment approaches to a decentralized community based approach. This shift is founded on evidence that in many poor countries, the majority of children with SAM are never brought to health facilities and in therefore an approach with a strong community component could provide them appropriate care [6]. However, two trials comparing children treated in outpatient care after one week of stabilization in inpatient setting against full inpatient care have shown differences in outcomes. The first trial in Malawi reported better results for outpatients than inpatients (recovery: $72 \%$ vs $49 \%$ ) probably related to more infections in inpatient care. The mortality rate was $5.4 \%$ for inpatient care and $3.0 \%$ for home-based therapy [7]. The second trial in Bangladesh reported the reverse (recovery: $67 \%$ vs $86 \%$ ) but no food supplements were provided to outpatients. The mortality rate was $3.5 \%$ in inpatient, $5 \%$ in day care and $3.5 \%$ at home after one week of day care [8].

Severe acute malnutrition still contributes significantly to in patient morbidity and mortality in Kenyan hospitals. The recovery rate from SAM in the outpatient management in Kenya is low. A study done in Nairobiin 2012 reported 58\% of recovery rate [9]. However, there is limited information on factors that facilitate or hinder the recovery rate. This study, therefore aimed to determinefactors associated with the recovery rate of children aged 6-59 months presenting with SAM in the OTPin Kitui County Hospital.

\section{Materials and Methods}

\subsection{Study Design and Settings}

We carried out a cross sectional study in Kitui County Hospital, Kenya. Patients who are enrolled to the Outpatient Therapeutic Programme (OTP)are referred from Maternal Child Health $(\mathrm{MCH})$ clinics after routine screening or inpatient paediatric wards orfrom their homes by community health workers (CHWs).

\subsection{Study Population and Sampling Technique}

The study population consisted of all children aged 6-59 months with SAM enrolled in OTP. Children with SAM enrolled in OTP had to have, according to WHO reference classification, $\mathrm{W} / \mathrm{H}<-3 \mathrm{Z}$-score, MUAC $<11.5 \mathrm{~cm}$, a good appetite, without medical complications and absence of severe or moderate edema. Approximately 70children new to OTP are seen every month. We anticipated to recruit patients for two months and a follow up period of one month. Using Israel (1992) [10] formula the representative sample size for the two months was estimated to be 104. These were recruited consecutively to the study. After recruitment, they were followed up on a weekly appointment for four visits.

\subsection{Data Collection and Data Quality Control}

Information was obtained from mothers/guardians regarding socio-demographic, socio-economic, socio-cultural and medical related factors. In addition, anthropometric measurements, physical examination and appetite test on children were conducted in a private room within the OTP clinic. Anthropometric measurements were conducted at the fourth visit. Recovery was defined when children attained target $\mathrm{W} / \mathrm{H}-2 \mathrm{Z}$-score, MUAC $>11.5 \mathrm{~cm}$ and above at the fourth visit. The study was pre-tested with $5 \%$ of the study's sample size.

\subsection{Ethical Considerations}

Study approval was sought from the Kenyatta National Hospital/ university of Nairobi Ethics and Research committee (KNH/UON-ERC). Administrative permission from the Kitui County Hospital was also granted. Informed written consent was obtained from all mothers/guardians of the children. Privacy and confidentiality were maintained while handling participants' information.

\subsection{Data Management and Analysis}

Data was cleaned and entered into Statistical Package for social sciences (SPSS) version 20.0 for analysis. Exploratory analysis was done to describe the study participants.

Descriptive analysis using frequency and proportions were computed for categorical variables. For continuous data, measures of central tendency were used. Chi-square test and odds ratio with corresponding $95 \%$ confidence interval were used to determine the association between recovery rate and independent variables. The significant factors with $\mathrm{p}$-value $<0.05$ at bivariate analysis were subjected to binary logistic regression by specifying 'backward $L R$ ' method with removal at $\mathrm{p}<0.05$.

\section{Results}

\subsection{Socio-Demographic, Socio-Cultural and Medical Related Characteristics of the Children}

We recruited 104 childreninto the study of which 3 were lost to follow up. The remaining 101 were followed up to four visits. Of these, $57(56.4 \%)$ were females witha mean ( \pm SD) age of $18( \pm 18.4)$ months. The highest proportion of malnourished children were in the age category of 6-12 months 35(34.7\%), followed by those aged 13-18 months $28(27.7 \%)$. Majority $71(70.4 \%)$ of the children were introduced to complementary foods at 6 months. About two thirds $66(65.3 \%)$ of the children were sharing food with the rest of the family from the same plate. More than half $59(58.4 \%)$ were still breastfeeding at the time of data collection. Forty (39.6\%) of the children were feeding3 times per dayand similar proportion were fed 4 times per day (Table 1). Nearly two thirds of the children 63(62.4\%) had a co-morbidity. Slightly less than half of the children 48 $(47.5 \%)$ of the children were given antibiotics (Table 1). 
Table 1. Socio-demographic, socio-cultural and medical related characteristics of the children.

\begin{tabular}{|c|c|c|}
\hline Variable & $\mathrm{N}=\mathbf{1 0 1}$ & $\%$ \\
\hline \multicolumn{3}{|l|}{ Age in months } \\
\hline 6-12 months & 35 & 34.7 \\
\hline 13-18 months & 28 & 27.7 \\
\hline 19-24 months & 23 & 22.8 \\
\hline 25-56 months & 15 & 14.8 \\
\hline Mean of age in months $( \pm \mathrm{SD})$ & \multicolumn{2}{|c|}{$18.07( \pm 18.4)$} \\
\hline \multicolumn{3}{|l|}{ Gender } \\
\hline Male & 44 & 43.6 \\
\hline Female & 57 & 56.4 \\
\hline \multicolumn{3}{|c|}{ Child's age at introduction of complementary food } \\
\hline 2-4 month & 15 & 14.8 \\
\hline 5 month & 15 & 14.8 \\
\hline 6 month & 71 & 70.4 \\
\hline \multicolumn{3}{|c|}{ Sharing of food from the same plate } \\
\hline Yes & 66 & 65.3 \\
\hline No & 35 & 34.7 \\
\hline \multicolumn{3}{|l|}{ Frequency of feeding per day } \\
\hline 3 times & 40 & 39.6 \\
\hline 4 times & 40 & 39.6 \\
\hline 5 or 6 times & 21 & 20.8 \\
\hline \multicolumn{3}{|l|}{ Illness in the last one month } \\
\hline Yes & 63 & 62.4 \\
\hline No & 38 & 37.6 \\
\hline \multicolumn{3}{|l|}{ Whether antibiotic given } \\
\hline Yes & 48 & 47.5 \\
\hline No & 53 & 52.5 \\
\hline
\end{tabular}

\subsection{Socio-Demographic and Economic Attributes of the Mothers/Guardians}

More than $90 \%$ of the guardians/parents lived on less than US \$50 monthly. About half of respondents 49(48.5\%) were within the age group of 25-35 years, 26(25.7\%) were between 18-24 years and 26(25.7\%) were among 36 years and above. Majority 62(61.4\%) attended primary school while only $9(8.9 \%)$ never attended school. More than half $56(55.4 \%)$ of the mothers/guardians were married (Table 2$)$.

Fifty $(49.5 \%)$ of the mothers/guardians were housewives, $29(28.7 \%)$ were in formal employment and $22(21.8 \%)$ were casual laborers. Ninety per cent of the families were living in temporary houses. The main source of water was river/stream(almost 70\%) (Table 2).

Table 2. Socio-demographic and economic attributes of the mothers/guardians.

\begin{tabular}{lll}
\hline Variable & $\mathbf{N = 1 0 1}$ & $\mathbf{\%}$ \\
\hline Mother's/guardian's age in years & & \\
18-24 years & 26 & 25.7 \\
25-35 years & 49 & 48.5 \\
36 years and above & 26 & 25.7 \\
Mother's/guardian's level of education & & \\
Never attended school & 9 & 8.9 \\
Primary & 62 & 61.4 \\
\hline
\end{tabular}

\begin{tabular}{lll}
\hline Variable & $\mathbf{N}=\mathbf{1 0 1}$ & $\mathbf{\%}$ \\
\hline Secondary and above & 30 & 29.7 \\
Mother's/guardian's religion & & \\
Christian & 97 & 96 \\
Muslim & 2 & 2 \\
Other & 2 & 2 \\
Mother's/guardian's marital status & & \\
Single & 30 & 29.7 \\
Married & 56 & 55.4 \\
Widowed/Divorced & 15 & 14.9 \\
Mother's/guardian's occupation & & \\
Casual labourer & 22 & 21.8 \\
Employed & 29 & 28.7 \\
House wife & 50 & 49.5 \\
Monthly Income in Ksh. & & \\
$<3000$ & 60 & 59.4 \\
3000-5000 & 27 & 26.7 \\
5000-10000 & 8 & 7.9 \\
$>10000$ & 6 & 5.9 \\
Type of house & & \\
Permanent(stone) & 10 & 9.9 \\
Semi-permanent (bricks) & 53 & 52.5 \\
mud thatched with grass & 38 & 37.6 \\
Source of water & & \\
Piped water & 7 & 6.9 \\
Borehole & 24 & 23.8 \\
River/stream & 73 & 69.3 \\
\hline
\end{tabular}

\subsection{Recovery Rate}

At the $4^{\text {th }}$ clinic visit $74(73.3 \%)$ of the children with SAM had recovered to $\mathrm{WHZ}$ score $-2 \mathrm{SD}$ and above $(95 \% \mathrm{CI}=$ 64.6-81.9).

\subsection{Factors Associated with Recovery}

In the bivariate analysis, appropriate introduction of complementary foods, absence of co-morbidities in the previous month, administration of antibiotics, higher mother's/guardian's level of education, and being a housewifewere associated with a higher recovery rate.

Multiple regression analysis (Table 3) showed that children who were introduced to complementary feeds at the age of 6 months were 9 times $[\mathrm{AOR}=8.86 ; 95 \% \mathrm{CI}=2.20$ $35.68 ; \mathrm{P}=0.002]$ and 5 months were 7 times $[\mathrm{AOR}=7.0$; $95 \% \mathrm{CI}=1.18-41.35 ; \mathrm{P}=0.032]$ more likely to recover from SAM as compared to those introduced within two to four months. Children who did not experience co-morbidities in the previous one month were 5 times $[\mathrm{AOR}=5.23$; $95 \% \mathrm{CI}=1.36-20.10 ; \mathrm{P}=0.016]$ more likely to recover from SAM when compared to children who had co-morbidities. Children given antibiotics were 13 times $[\mathrm{OR}=13.06$; $95 \% \mathrm{CI}=3.01-56.65 ; \mathrm{P}=0.001]$ more likely to be recovered from SAM than those who were not given.

Children whose mothers/guardians were house wives were 5 times $[\mathrm{AOR}=5.26 ; 95 \% \mathrm{CI}=1.33-20.87 ; \mathrm{P}=0.018]$ more likely to recover from SAM on outpatient management programthan to children whose mothers/guardians were casual laborers. 
Table 3. Factors associated with recovery rate.

\begin{tabular}{|c|c|c|c|c|c|c|}
\hline \multirow{2}{*}{ Variables } & \multicolumn{2}{|l|}{ Recovery } & \multirow[t]{2}{*}{$\mathrm{OR}^{\psi}\left(95 \% \mathrm{CI}^{\varphi}\right)$} & \multirow[t]{2}{*}{ P value* } & \multirow[t]{2}{*}{$\operatorname{AOR}^{\infty}\left(95 \% \mathrm{CI}^{\varphi}\right)$} & \multirow[t]{2}{*}{ P value* } \\
\hline & Yes, $\mathbf{n}(\%)$ & No, $n(\%)$ & & & & \\
\hline \multicolumn{7}{|l|}{ Child's age in months } \\
\hline 6 to 12 & $23(65.7 \%)$ & $12(34.3 \%)$ & 1.00 & & & \\
\hline $13-18$ & $24(85.7 \%)$ & $4(14.3 \%)$ & $3.13(0.88-11.12)$ & 0.078 & - & - \\
\hline $19-24$ & $16(69.6 \%)$ & $7(30.4 \%)$ & $1.19(0.39-3.69)$ & 0.760 & & \\
\hline $25-56$ & $11(73.3 \%)$ & $4(26.7 \%)$ & $1.44(0.38-5.48)$ & 0.598 & & \\
\hline \multicolumn{7}{|l|}{ Child's gender } \\
\hline Male & $30(68.2 \%)$ & $14(31.8 \%)$ & 1.00 & & - & - \\
\hline Female & $44(77.2 \%)$ & $13(22.8 \%)$ & $1.58(0.65-3.83)$ & 0.312 & & \\
\hline \multicolumn{7}{|c|}{ Child's age at introduction of complementary food } \\
\hline $2-4$ month & $7(46.7 \%)$ & $8(53.3 \%)$ & 1.00 & & 1.00 & \\
\hline 5 month & $10(66.7 \%)$ & $5(33.3 \%)$ & $2.29(0.52-10.01)$ & 0.273 & $7.00(1.18-41.35)$ & 0.032 \\
\hline 6 month & $57(80.3 \%)$ & $14(19.7 \%)$ & $4.65(1.44-15.00)$ & 0.010 & $8.86(2.20-35.68)$ & 0.002 \\
\hline \multicolumn{7}{|l|}{ Sharing of food from the same plate } \\
\hline Yes & $48(72.7 \%)$ & $18(27.3 \%)$ & 1.00 & & - & - \\
\hline No & $26(74.3 \%)$ & $9(25.7 \%)$ & $1.08(0.43-2.75)$ & 0.866 & & \\
\hline \multicolumn{7}{|l|}{ Frequency of feeding per day } \\
\hline 3 times & $29(72.5 \%)$ & $11(27.5 \%)$ & 1.00 & & & \\
\hline 4 times & $29(72.5 \%)$ & $11(27.5 \%)$ & $1.00(0.38-2.67)$ & 1.000 & - & - \\
\hline 5 or 6 times & $16(76.2 \%)$ & $5(23.85)$ & $1.21(0.36-4.11)$ & 0.756 & & \\
\hline \multicolumn{7}{|l|}{ Illness in the last one month } \\
\hline Yes & $41(65.1 \%)$ & $22(34.9 \%)$ & 1.00 & & 1.00 & \\
\hline No & $33(86.8 \%)$ & $5(13.2 \%)$ & $3.54(1.21-10.36)$ & 0.021 & $5.23(1.36-20.10)$ & 0.016 \\
\hline \multicolumn{7}{|l|}{ Whether antibiotic given } \\
\hline Yes & $43(89.6 \%)$ & $5(10.4 \%)$ & $6.10(2.08-17.89)$ & 0.000 & $13.06(3.01-3.01)$ & 0.001 \\
\hline No & $31(58.5 \%)$ & $22(41.5 \%)$ & 1.00 & & 1.00 & \\
\hline \multicolumn{7}{|l|}{ Mother's/guardian'sage in years } \\
\hline $18-24$ years & $19(73.1 \%)$ & $7(26.9 \%)$ & 1.00 & & & \\
\hline $25-35$ years & $36(73.5 \%)$ & $13(26.5 \%)$ & $1.02(0.35-2.99)$ & 0.971 & - & - \\
\hline 36 years and above & $19(73.1 \%)$ & $7(26.9 \%)$ & $1.00(0.29-3.41)$ & 1.000 & & \\
\hline \multicolumn{7}{|l|}{ Mother's/guardian'slevel of education } \\
\hline Never attended & $4(44.4 \%)$ & $5(55.6 \%)$ & 1.00 & & 1.00 & \\
\hline Primary & $44(71.0 \%)$ & $18(29.0 \%)$ & $3.06(0.74-12.70)$ & 0.124 & $2.96(0.58-15.16)$ & 0.194 \\
\hline Secondary and above & $26(86.7 \%)$ & $4(13.3 \%)$ & $8.13(1.51-43.78)$ & 0.015 & $8.10(0.99-56.38)$ & 0.055 \\
\hline \multicolumn{7}{|l|}{ Mother's/guardian'smarital status } \\
\hline Single & $23(76.7 \%)$ & $7(23.3 \%)$ & 1.00 & & & \\
\hline Married & $40(71.4 \%)$ & $16(28.6 \%)$ & $0.76(0.27-2.12)$ & 0.601 & - & - \\
\hline Widowed/divorced & $11(73.3 \%)$ & $4(26.7 \%)$ & $0.84(0.20-3.47)$ & 0.806 & & \\
\hline \multicolumn{7}{|l|}{ Mother's/guardian'soccupation } \\
\hline Casual labourer & $13(59.1 \%)$ & $9(40.9 \%)$ & 1.00 & & 1.00 & \\
\hline Employed & $19(65.5 \%)$ & $10(34.5 \%)$ & $1.34(0.42-4.13)$ & 0.639 & $1.18(0.32-4.39)$ & 0.805 \\
\hline House wife & $42(84.0 \%)$ & $8(16.0 \%)$ & $3.64(1.17-11.34)$ & 0.026 & $5.26(1.33-20.87)$ & 0.018 \\
\hline \multicolumn{7}{|l|}{ Income } \\
\hline$<3000$ & $47(78.3 \%)$ & $13(21.7 \%)$ & 1.00 & & & \\
\hline $3000-5000$ & $19(70.4 \%)$ & $8(29.6 \%)$ & $0.66(0.24-1.84)$ & 0.424 & - & - \\
\hline$>5000$ & $8(57.1 \%)$ & $6(42.9 \%)$ & $0.37(0.11-1.25)$ & 0.110 & & \\
\hline Type of house & & & & & & \\
\hline Permanent(stone) & $5(50.0 \%)$ & $5(50.0 \%)$ & 1.00 & & - & \\
\hline Semi-permanent (bricks) & $39(73.6 \%)$ & $14(26.4 \%)$ & $2.79(0.70-11.09)$ & 0.146 & & - \\
\hline Temporary (mud thatched with grass) & $30(78.9 \%)$ & $8(21.1 \%)$ & $3.75(0.87-16.22)$ & 0.077 & & \\
\hline Source of water & & & & & & \\
\hline Piped water & $5(71.4 \%)$ & $2(28.6 \%)$ & 1.00 & & & \\
\hline Borehole & $21(87.5 \%)$ & $3(12.5 \%)$ & $2.80(0.37-21.49)$ & 0.322 & - & - \\
\hline River/stream & $48(68.6 \%)$ & $22(31.4 \%)$ & $0.87(0.16-4.85)$ & 0.876 & & \\
\hline
\end{tabular}

${ }^{*}$ Significant at $\mathrm{p}<0.05$ bolded; ${ }^{\psi}$ Odds ratio; ${ }^{\infty}$ AdjustedOdds ratio; ${ }^{\varphi} 95 \%$ Confidence Interval

\section{Discussion}

Thereduced probability of recovery among children with co-morbidity in the previous one monthwas likely because SAM and illness may lead to reduced appetite, which could lead to poor nutrient intake or poor absorption of essential nutrients [11]. Poor nutrient intake will subsequently affect weight gain and recovery [12]. It is also reported that undernutrition and childhood morbidity have a synergistic relationship. The interrelationship of the two is in such a way that illness can suppress appetite precipitating under-nutrition of a child while, on the other hand, nutritional deficiencies increase the susceptibility of the child to infectious diseases 
[13]. Infection can suppress appetite and directly affect nutrient metabolism, leading to poor nutrient utilization. This may explain the finding of this study that patients with fewer comorbidities had better outcomes.

Children given antibioticswere more likely to recover from SAMthan to those who were not. Despite the absence of clinical signs, severely malnourished children are nearly all infected with bacteria even if they are asymptomatic. This includes those with moderate, and some with good appetite [14]. Enteric bacteria are frequently the source of systemic infection by translocation across the bowel wall. Untreated gut or systemic infection can cause mal-absorption, intestinal damage and subsequently lead to diarrhea. The consumed nutrients are either not absorbed or they are lost through diarrhea leading to poor response to nutritional therapy.

In this study, introduction of complementary foods at 6 months of age was significantly associated with higher recovery rate. Children introduced with complementary foods at the age of 6 monthsweremore likely to recover than those given complimentary feeds within two months. World Health Organization and UNICEF recommend a baby should exclusively breast feed for six months [15]. Introducing these foods too early reduces the amount of breast milk the child is taking and may introduce the child to pathogens and subsequent diarrheal diseases. In most cases in developing countries, these foods are not tailored to the needs of the infant [16]. Most of the solid foods are lower in caloric content, of lower nutritional value, and can be difficult for young babies to digest than human milk. Many foods if introduces before six months can cause unpleasant reactions and even trigger allergies in babies with allergic predisposition [17]. Complementary feeding should be timely, adequatein terms of amounts, frequency, consistency and variety of foods to cover the nutritional needs of the growing child while maintaining breastfeeding for good recovery.

The finding from this study that children whose mothers were housewives were more likely to recover from SAM on outpatient management than those children whose mothers/guardians were casual laborers suggests that children who spend more time with their caregivers have better outcomes. This could be due to the fact that housewives are with their babies most of the time and therefore they may give more attention to their children including feeding them. On the contrary mothers/guardians who are casual laborers may have less time for child care which can lead to poor recovery rate. Studies have shown that women who labour to acquire wages have less time for child care [18].

\section{Conclusion}

There is need for caregivers to spend time with their children for these children to have better outcomes. It is imperative that complimentary feeding is not started before the recommended time to improve health status of infants. There is need to prevent children from getting infections and to treat them appropriately with antibiotics when they get these infections.

\section{List of Abbreviations}

AOR: Adjusted Odds Ratio; CI: Confidence Interval; CHWs: Community Health Workers; KNH/UON: Kenyatta National Hospital/University of Nairobi; MCH: Maternal and Child Health; MUAC: Middle Upper Arm Circumference; OR: Odds Ratio; OTP: Outpatient Therapeutic Program; RUTF: Ready to Use Therapeutic Food; SAM: Severe Acute Malnutrition; SPSS: Statistical Package for Social Sciences; UNICEF: United Nations Children's Fund; WHO: World Health Organization;

\section{Competing Interests}

The authors declare that they have no competing interests.

\section{Authorship Contribution}

$\mathrm{DM}$, contributed in conceptualizing the idea, design of the study, collecting of data and in drafting manuscript. LKB, AKK, $\mathrm{BO}$ and DW were involved in technical guidance in the design, participated in coordination of the study and involved in revising manuscript critically for important intellectual content. MHF performed statistical analysis and interpretation of data and helped to draft the manuscript. Each author has given final approval of the version to be published.

\section{Acknowledgements}

The funding is from the Linked-Strengthening Maternal, Newborn and Child Health Research Training in Kenya. The grant is linked to Partnership for Innovative Medical Education in Kenya (PRIME-K). The project described was supported by Award Number 5R24TW008907 and R24TW008889 from the US National Institutes of Health. The content is solely the responsibility of the authors and does not necessarily represent the official views of the US National Institutes of Health. The authors would also like to sincerely appreciate all the study participants for their time and willingness to participate. The authors also give special thanks to the medical superintendent, data collectors and all staff members of Kitui County Hospital for their cooperation during the collection of data for this study and allowing us to conduct this research.

\section{References}

[1] World Health Organization and United Nations Children's Fund, 'WHO child growth standards and the identification of severe acute malnutrition in infants and children: A joint statement by the World Health Organization and the United Nations Children's Fund, 2008.

[2] World Health Organization (WHO), World Food Programme (WFP), the United Nations Standing Committee on Nutrition (UN/SCN) and the United Nations Children's Fund (UNICEF). Joint Statement. Community-based management of severe acute malnutrition, Geneva, WHO, 2007. 
[3] Collins S, Sadler K, Dent N, Khara T, Guerrero S, Myatt M, Saboya M, Walsh A. Key issues in the success of communitybased management of severe malnutrition. Food Nutr Bull 2006; 27(suppl): S49-82.

[4] Black R. E., Morris S. S., Bryce J. Where and why 10 million children are dying every year? Lancet child survival series 1 , 2003; 361: 2226-2234.

[5] Kenya National Bureau of Statistics (KNBS) and ICF Macro: Kenya Demographic and Health Survey 2008-09 report Calverton, Maryland, U.S.A; 2010.

[6] UNICEF, (2012). Evaluation of Integrated Management of Acute Malnutrition (IMAM): Kenya Country Case Study. New York.

[7] Ciliberto MA, Sandige H, Ndekha MJ, Ashorn P, Briend A, Ciliberto HM, and Manary MJ. Comparison of home-based therapy with ready-to-use therapeutic food with standard therapy in the treatment of malnourished Malawian children: a controlled, clinical effectiveness trial. American Journal of Clinical Nutrition, 2005, 81: 864-870.

[8] Khanum S, Ashworth A, Huttly SR. Controlled trial of three approaches to the treatment of severe malnutrition. Lancet, 1994, 344: 1728-1732.

[9] Nalwa G. M. Outcomes of severely malnourished children aged 6 to 60 months on outpatient management, Nairobi, Kenya. 2012.

[10] Israel, G. D. Sampling: The Evidence of Extension Program Impact. Program Evaluation and Organizational Development,
IFAS, University of Florida; PEOD-5, 1992; Retrieved from http://edis.ifas.ufl.edu/pdffiles/PD/PD00500.pdf3/6/2011.

[11] Macallan D. Malnutrition and infection. Medicine. 2005, 33(3): 14-16.

[12] Golden MH. In Garrow JS, James WPT, Ralph A. Human nutrition and dietetics. Tenth edition. Churchill Livingston. London 2000.

[13] Pelletier DL, Frongillo EA Jr, Schroeder DG, Habicht JP. The effects of malnutrition on child mortality in developing countries. Bull World Health Organ 1995; 73: 443-8.

[14] Shils M, Shike M, Ross C, Cballero B, Cousins R (2006) Modern Nutrition in Health and Disease. Lippincott Williams \& Wilkins, 10th ed.

[15] WHO/UNICEF. Complementary feeding of young children in developing countries: a review of current scientific knowledge (WHO/Nut/98.1) Geneva: world Health organisation, 1998.

[16] Kikafunda, J. K., Walker, A. F., and Tumwine, J. Weaning foods and Practices in Central Uganda; Cross sectional studies. African Journal of Food, Agriculture, Nutrition and Development, 2003, 3(2) 1-18.

[17] Greer, F., Sicherer, S. \& Burks, A. Effects of early nutritional interventions on the development of atopic disease in infants and children: the role of maternal dietary restriction, breastfeeding, timing of introduction of complementary foods, and hydrolyzed formulas. Pediatrics, 2008, 121, 183-191.

[18] Lipton, M., de Kadt, E. Agriculture-Health Linkage. WHO Offset Publication No 104. WHO Geneva, 1998. 